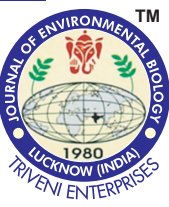

\title{
Biodegradation of 4-nitrophenol by a Rhodococcus species and a preliminary insight into its toxicoproteome based on mass spectrometry analysis
}

\begin{tabular}{lll}
\hline Paper received: 26.05.2018 Revised received: $13.10 .2018 \quad$ Re-revised received: 24.10.2018 & Accepted: 19.11 .2018
\end{tabular}

\section{Authors Info \\ K. Sengupta', M. Alam², S. Pailan ${ }^{1}$ and P. Saha ${ }^{1 *}$ \\ 'Department of Microbiology, \\ Burdwan University, \\ Burdwan-713 104, India \\ 2Department of Microbiology, Bose Institute, Kolkata-700 054, India \\ *Corresponding Author Email : psaha@microbio.buruniv.ac.in}

\section{Edited by \\ Dr. G.K. Sivaraman}

Reviewed by

Dr. Baskar Gurunathan

Dr. M. A. Rasheed

\section{Abstract}

Aim : The objective of this study was to understand the possible fate of 4-NP through the molecular mechanism and to identify potential enzymes involved in 4-NP biodegradation by Rhodococcus sp. strain BUPNP1.

Methodology : Biodegradation of 4-NP was detected spectrophotometrically at $400 \mathrm{~nm}$ and also confirmed by TLC and HPLC. Comparative study of proteomes was performed by 2-D gel electrophoresis followed by peptide mass fingerprinting and bioinformatic analysis to identify and/ or predict the possible functions of over-expressed proteins in 4-NP treated cells of BUNP1.

Results : Utilization of 4nitrophenol and its hydrolysis intermediate 4-nitrocatechol (4$\mathrm{NC}$ ) and 1,2,4-Benzenetriol as sole carbon source indicated the presence of genomic information encoding the enzyme necessary for the operation of 4-nitrophenol degradation pathway in the strain BUPNP1. It could transform 4-NP into 4-NC by monooxygenase whose major activity was detected during initial stage of degradation. The 4-NC further depleted in the medium to release nitrite ions. In order to investigate the molecular changes occurring during degradation, a comparative study of proteome profiles was carried out where; 4-

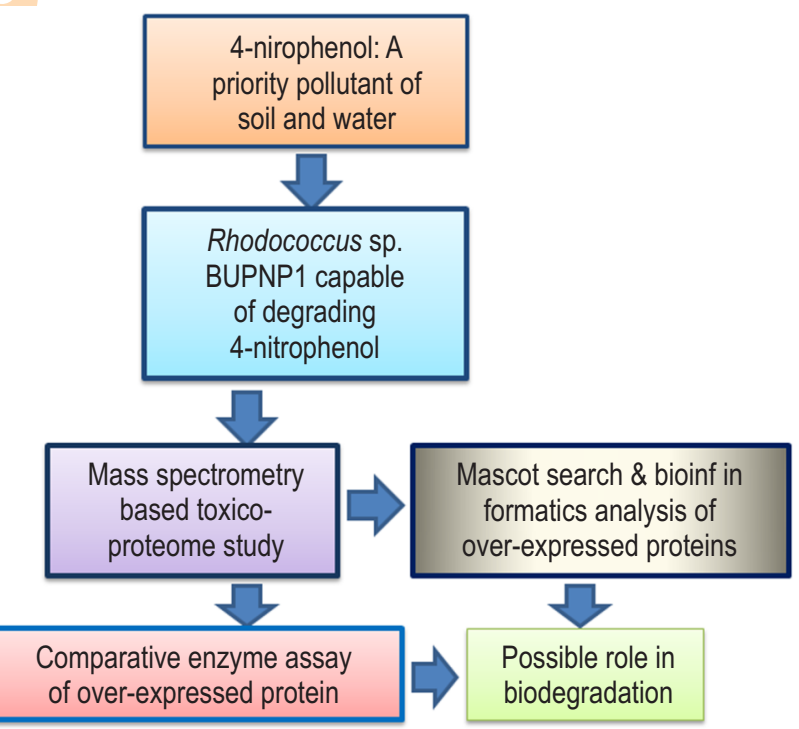
nitrophenol treated cells were compared against cells grown on glucose as control. The comparative study indicated expression of several protein spots under 4-nitrophenol treated condition.

Interpretation: This study showed the potential of BUPNP1 strain belonging to genus Rhodococcus towards induced expression of some unique proteins which might have possible role in 4-NP biodegradation process.

Key words: 4-Nitrophenol, Biodegradation, Rhodococcus, Toxicoproteome, Xenobiotic

How to cite : Sengupta, K., M. Alam, S. Pailan and P. Saha: Biodegradation of 4-nitrophenol by a Rhodococcus species and a preliminary insight into its toxicoproteome based on mass spectrometry analysis. J. Environ. Biol., 40, 356-362 (2019). 


\section{Introduction}

A xenobiotic nitroaromatic compound, 4-nitrophenol (4$N P$ ) is considered as one of the priority pollutant as per environmental protection agency of United States and a commodity chemical which finds its uses in the manufacturing of pesticides, dyes, petrochemicals and pharmaceuticals (Leilei et al., 2012; Rubio et al., 2012; Kalbende et al., 2013). In addition to this, 4-NP is fairly water soluble, toxic metabolite released into agricultural soils from the microbial degradation of parathion, methyl parathion and other agrochemicals and is adversely correlated with several human health issues (Wei et al., 2010; Arora, 2012). Microbial degradation is primarily responsible for the removal of 4-NP from the environment and several bacteria have been reported to degrade it (Shen et al., 2010; Pirie et al., 2011; Arora et al., 2014). Microbial bioremediation of polluted soil has gained popularity mainly due to its cost effectiveness, ecofriendly, clean approach that does not generate toxic secondary constituents unlike physical, chemical and physico-chemical approaches (Kou-San and Parales, 2010; Pino et al., 2011).

Two major pathways of 4-NP biodegradation have been characterized so far, one degradation pathway leads to the formation of 4-nitrocatechol (4-NC) has been reported in Grampositive bacteria such as Arthrobacter spp., Bacillus spp., and Rhodococcus spp. (Liu et al., 2010; Vikram et al., 2012b; Sengupta and Saha, 2014; Sengupta et al., 2015) and other leads to formation of Hydroquinone has been reported in Gramnegative bacteria such as Sphingomonas sp., Moraxella spp. and Pseudomonas spp. (Kolvenbach et al., 2011; Zhang et al., 2012; Zhang et al., 2015). However, both 4-NP catabolic pathways through formation of $\mathrm{HQ}$ and 4-NC are present in Burkholderia sp. SJ98 (Vikram et al., 2012a). Although a large number of bacteria have been isolated and reported as potential degrader of nitroaromatic pollutants (Chauhan et al., 2010; Ghosh et al., 2010; Arora et al., 2012; Min et al., 2016), very little is known regarding the molecular changes involved in biodegradation mechanisms. For example, existing literature on studies carried out with the members of the order Actinomycetales revealed that the members of this group have evolved the metabolic enzymes or enzyme systems which can selectively remove nitro group from parent compounds by oxidative or reductive means, resulting in productive catabolism of nitroaromatic compounds (Ghosh et al., 2010; Kou-San and Parales, 2010).

Among them rhodococci are of great interest because of their remarkable metabolic diversity and they have been shown to exhibit a unique range of enzyme activities which help them to degrade diverse classes of xenobiotic compounds (Ghosh et al., 2010; Rasheed et al., 2013; Min et al., 2016). The effect of a toxicant to a particular proteome, i.e., toxicoproteomics (Kooken et al., 2014) has not been reported in Rhodococcus sp., thus to get insight into its toxicoproteome, a comparative proteomic study was undertaken. This approach involved comparison of whole cell protein profiles from bacterium after growing them under test versus control conditions, combined with bioinformatics analyses provides powerful techniques to monitor (and identify proteins) specific changes occurring under a defined set of conditions (Karpievitch et al., 2010; Alam and Ghosh, 2014); with respect to qualitative and quantitative aspects of proteins having possible role in the degradation process and is helpful in bioengineering of bacterial strains to clean up polluted sites more efficiently (Karigar and Rao, 2011).

Rhodococcus sp. BUPNP1 was isolated from a land fill soil and could transform 4-NP to 4-NC and utilized both 4-NP and 4-NC as sole carbon sources for growth. In view of the above, the objective of this study was to comprehend the fate of 4-NP, the molecular mechanism and to identify potential enzymes involved in 4-NP biodegradation by Rhodococcus.

\section{Materials and Methods}

Bacteria and culture conditions: Rhodococcus sp. BUPNP1 was isolated from a landfill soil sample in Burdwan by enrichment culture technique, deposited at Microbial culture collection, National Centre of Cell Science, Pune, India (MCC2337) and regularly grown in Tryptic soya broth at $37^{\circ} \mathrm{C}$ in incubator shaker with $120 \mathrm{rpm}$ and maintained in Tryptic soya agar plates at $37^{\circ} \mathrm{C}$. Growth, 4-NP depletion and 4-NC formation as intermediate by the strain was optimized on a minimal salt medium (MS medium, Prakash et al., 1996) supplemented with $0.5 \mathrm{mM}$ of 4-NP. Growth of the culture was measured at $\mathrm{OD}_{600}$ and the residual 4-NP at $\mathrm{OD}_{400}$ using a UV-VIS spectrophotometer (VARIAN, Cary50 Bio UV-VIS spectrophotometer). Controls were incubated without cells to measure abiotic 4-NP degradation which was recorded to be very low. Growth of the strain on other intermediate metabolites such as 4-NC $(0.3 \mathrm{mM})$ and $\mathrm{BT}(0.3 \mathrm{mM})$, as sole carbon source, was also checked by using the same MS medium. All readings were measured in triplicate to obtain standard deviation for each recorded value.

Identification of nitrite release and HPLC analysis of 4-NP pathway intermediates: Release of nitrite ions was detected spectrophotometrically using an equal volume of reagent $A$ $(0.1 \%, \mathrm{w} / \mathrm{v}, \mathrm{N}$-ethylene diamine dihydrochloride in $30 \% \mathrm{v} / \mathrm{v}$ acetic acid was added to culture supernatants (Ghosh et al., 2010). After $2 \mathrm{~min}$, an equal volume of reagent $\mathrm{B}(0.1 \%$, w/v, sulfanilic acid in $30 \%, v / v$ acetic acid) was added and incubated for $30 \mathrm{~min}$. The appearance of purple color indicated the release of nitrite ions which was quantified by measuring absorbance at $540 \mathrm{~nm}$, against the standard curve of $\mathrm{NaNO}_{2}$. In order to identify the 4-NP metabolic pathway intermediates by HPLC, extraction of culture residue was performed as per Ghosh et al. (2010). The culture (10 $\mathrm{ml}$ ) was aseptically withdrawn, centrifuged at $8000 \mathrm{rpm}$ for $10 \mathrm{~min}$ and supernatant was collected for extraction using equal volume of ethyl acetate, both acidic and neutal extraction was done followed by dehydration using anhydrous sodium sulphate and evaporated to dryness. The dried sample was dissolved in appropriate volume of acetonitrile, filtered through sterile disposable syringe filter (Millipore, $0.22 \mu \mathrm{m}$ ) and subjected to HPLC analyses. HPLC was performed on a $\mathrm{HiQ}$ sil $\mathrm{C}_{18} \mathrm{HiQ}$ Sil 
column (250 mm X 4.6 ID) with UV/VIS absorbance detector and SHIMAZDU HPLC pump (SPD-M20A). For estimation of residual 4-NP in MM and to detect 4-NP and its intermediate metabolites of degradation pathways, a gradient of acetonitrile: water (80:20 to $0: 100$ ) was used as the mobile phase at a flow rate of $1 \mathrm{ml} \mathrm{min}^{-1}$ and UV-VIS detector was monitored at $310 \mathrm{~nm}$. Compounds were identified by comparing retention time of the test samples to that of authentic reference standards (Ghosh et al., 2010).

Preparation of cell free extract for proteomics study: The cells of strain BUPNP1 were collected at different time points from incubations grown on MM supplemented with $0.5 \mathrm{mM}$ of 4-NP and frozen at $-80^{\circ} \mathrm{C}$ for abolishing all metabolic activities. Cell free extract was prepared by thawing cells followed by ultrasonication (Hielcher UP50H, USA; 3 cycles, each lasting for 5 min at 275W) with intermittent pulse. Sonicated samples were centrifuged at $12000 \mathrm{rpm}$ at $4^{\circ} \mathrm{C}$ for 10 min to obtain crude cell extract. Similarly, the crude cell extract was prepared from glucose $(1 \% \mathrm{w} / \mathrm{v})$ grown cells for the strain. The cell free supernatant or crude extract was collected and later used for enzyme assays and also subjected to proteomics analysis. The amount of protein was estimated by using Bradford test kit (Quick start kit $^{\mathrm{TM}}$, BioRad) as per manufacturer's instructions.

One and two-dimensional gel electrophoresis (2-DE): Rhodococcus sp. strain BUPNP1 was grown to log phase in MS medium supplemented with $0.5 \mathrm{mM} 4-\mathrm{NP}$ as sole source of carbon. Cells grown in MS medium supplemented with $1 \%$ glucose as carbon source served as control. Cells from mid-log phase were collected and washed thrice with $0.2 \mathrm{M}$ phosphate buffer ( $\mathrm{pH} 7.0)$ and were subjected to freez-thaw lyses in modified extraction buffer with sucrose (EBS, containing $30 \% \mathrm{w} / \mathrm{v}$ sucrose, $500 \mathrm{mM}$ Tris-HCl (pH 8.5), $50 \mathrm{mM}$ EDTA, $100 \mathrm{mM} \mathrm{KCl,2 \%} \mathrm{v/v} \beta-$ mercaptoethanol, $1 \mathrm{mM}$ phenyl methyl sulfonyl fluoride (PMSF) and $0.15 \% \mathrm{w} / \mathrm{v} \mathrm{CHAPS}$ ). The cells were lysed by ultrasonication and incubated in ice for 20 min with periodic vortexing. Proteins were precipitates by following phenol extraction (PE) method for protein purification which is amenable to downstream 2-DE (Alam and Ghosh, 2014). Washed and dried protein pellets were resuspended in a Ready Prep rehydration buffer (BioRad) and quantified by Bradford method. An equal amount of protein ( 310 $\mu \mathrm{g}$ in $180 \mu \mathrm{l})$ in rehydration buffer were applied to IPG strips of 4-7 $\mathrm{pH}$ range and rehydrated for $16 \mathrm{~h}$ at $20^{\circ} \mathrm{C}$. Isoelectric focusing (IEF) was performed in initial linear ramping to $250 \mathrm{~V}$ for $20 \mathrm{~min}$ followed by linear ramping to $8000 \mathrm{~V}$ for $3 \mathrm{~h}$ with rapid ramping to $20000 \mathrm{Vh}$, and final eventual termination at $30000 \mathrm{Vh}$. The focused IPG strips were placed in second-dimension SDS-PAGE which was run at standard conditions as per previous report (Alam and Ghosh, 2014).

In gel digestion and mass spectrometry analysis: The overexpressed protein spots were excised manually, chopped into small pieces and treated as described earlier (Shevchenko et al. 2006) for peptide mass fingerprinting by using MALDI TOF TOF. Mass spectrophotometric analyses of the extracted peptides were performed using an AutoFlex II (Burker Daltonics) MALDI
TOF TOF machine equipped with a pulse $\mathrm{N}_{2}$ laser. MS of extracted peptide were analyzed by flex analysis software (version 2.4) and the processed peaks were transferred through the MS BioTools (version 3.0) program as input to MASCOT search engine (version 2.2) for protein identification for database search: database (NCBInr), taxonomy (Actinobacteria) was applied. All these protein were subjected to various other bioinformatics tools to obtain information about their intracellular position, presence of signal peptide, peptide domain etc.

Enzyme assays: Time course monooxygenase (4-NP MO) assay was performed as described earlier for Rhodococcus imtechensis (Ghosh et al., 2010). The reaction mixtures (final volume $1 \mathrm{ml}$ ) contained $75 \mu \mathrm{M}$ 4-NP, $300 \mu \mathrm{M}$ nicotinamide adenine diphosphate hydrogen (NADPH), $30 \mu \mathrm{M}$ flavin adenine dinucleotide (FAD), 0.53-0.97 mg ml${ }^{-1}$ of protein and $20 \mathrm{mM}$ phosphate buffer $(\mathrm{pH} 7.0)$. The reaction was initiated by addition of crude extract and incubated for $10 \mathrm{~min}$ at $37^{\circ} \mathrm{C}$. The molar extinction coefficient of $\mathrm{NAD}(\mathrm{P}) \mathrm{H}$ at $340 \mathrm{~nm}$ was detected as 6130 $\mathrm{M}^{-1} \mathrm{~cm}^{-1}$ at $\mathrm{pH}$ 7. ADH assay was performed by preparing reaction mixture (final volume $3 \mathrm{ml}$ ) containing $50 \mathrm{mM}$ phosphate buffer (pH 8.0), $5 \mathrm{mM} \mathrm{NAD+}$, and 0.53-0.97 $\mathrm{mg} \mathrm{ml}^{-1}$ of protein. The reaction was initiated by adding $99.9 \%$ ethanol (final concentration of $0.15 \mathrm{M}$ ). Spectrophotometric absorbance of $\mathrm{NADH}$ formation was recorded after $5 \mathrm{~min}$ at $340 \mathrm{~nm}$ and molar extinction coefficient of $\mathrm{NADH}$ was detected as $6220 \mathrm{M}^{-1} \mathrm{~cm}^{-1}$ at $\mathrm{pH}$ 8. The spectrophotometric absorbance for the enzyme assay was recorded in double beam UV-VIS spectrophotometer (SHIMADZU, UV-2600).

Statistical analysis: Experimental sets for enzyme assay were repeated in triplicates to determine standard deviation $( \pm S D)$ by using Statistical Package for the Social Sciences (SPSS).

\section{Results and Discussion}

Growth of strain BUPNP1 in minimal salt medium supplemented with 4-NP and its major hydrolytic intermediate 4$\mathrm{NC}$ and BT (Fig. 1A) indicated that it can utilize 4-NP $(0.5 \mathrm{mM})$, 4$\mathrm{NC}(0.3 \mathrm{mM})$ as well as $\mathrm{BT}(0.3 \mathrm{mM})$ as sole carbon source. The residual 4-NP detected by HPLC was quantified and recorded to decrease progressively with time during the growth of bacteria whereas the concentration of 4-NC increased up to $48 \mathrm{hrs}$ and then gradually decreased indicating its utilization and depletion in turn (Fig.1B). As evident from the Fig.1B, it was indicated that the strain could utilize $0.5 \mathrm{mM} 4-\mathrm{NP}$ as sole source of carbon with concomitant formation of 4-NC and release of nitrite ion during course of 4-NP degradation. The maximum concentrations of 4$\mathrm{NC}(0.44 \mathrm{mM})$ and nitrite ion $(0.16 \mathrm{mM})$ were detected at $48 \mathrm{hr}$ of culture extract. The presence of nitrite ions in the culture medium and depletion of 4-NC after $48 \mathrm{hr}$, was also an indication of 4-NC utilization as sole carbon source by this strain.

Through HPLC study, 4-nitrocatechol was confirmed as major intermediate during 4-NP degradation as was shown previously by TLC studies (Sengupta and Saha, 2014). Thus, 
overall speculation regarding the fate of 4-NP metabolism in the strain suggests that 4-NP degradation starts with formation of 4$\mathrm{NC}$ and further breaks down to release its nitrite ion and converts into TCA cycle intermediates for energy conversion.

Also, the percentage of 4-NP depletion and the enzyme activities are shown to be related as directly proportional (Fig. 2), which showed that conversion of 4-NP into 4-NC was mediated by MO enzyme. Specific enzyme activity of ADH and 4-NP MO was determined in crude cell extract obtained from different time interval of 4-NP degradation by the strain BUPNP1 and it was observed that maximum specific enzyme activity of $\mathrm{MO}(\sim 0.115$ $\left.\mathrm{mM} \mathrm{min}{ }^{-1} \mathrm{mg}^{-1}\right)$ was exhibited during early exponential growth (8$16 \mathrm{hr})$ and that of $\mathrm{ADH}\left(\sim 46 \mathrm{mM} \mathrm{min}^{-1} \mathrm{mg}^{-1}\right)$ was in late log phase of growth (24-32 hr). The conversion of 4-NP into 4-NC is mediated by NADH dependent MO enzyme (Yamamoto et al., 2011) which was detected positive (by enzyme assay) in the strain.

Also, concomitant release of nitrite ions indicated that the strain is capable to break 4-NC to release nitrite ions whose accumulation to some extent was detected quantitatively by a photometric assay. In addition, the strain showed its growth on all the intermediate metabolites of 4-NP degradation such as 4-NC and BT. Thus, the fate of the toxic compound 4-NP in the bacterium was speculated that it firstly get converted to 4-NC by $\mathrm{MO}$ enzyme, 4-NC is lesser toxic than 4-NP and more water soluble (Kou-San and Parales, 2010; Chi et al., 2013). 4-NC further breaks down to an unstable intermediate to release nitrite ions (Ghosh et al., 2010). A lower pathway intermediate BT was not detected by HPLC but the strain showed its growth on it, which indicated that the strain derives its energy from conversation of 4-
NC into lower metabolite to be used up in TCA cycle ultimately, this result also corroborate with previous reports (Ghosh et al., 2010; Subhaschandrabose et al., 2018).

The proteomes for strain BUPNP1 was isolated from both 4-NP (test) and glucose (as control) grown cells and analyzed initially, in one-dimension SDS-PAGE (12\%) where non-resolved over-expressed protein bands appearing within the range of 45$55 \mathrm{KD}$ a was detected in the presence of 4-NP. In order to identify a specific protein (if any), expressed under 4-NP treated condition, the total proteins extracted from the two above mentioned conditions were separated by using two-dimensional gel electrophoresis. The equal amount of proteins for both the conditions was loaded and proteins were separated first (by Isoelectric focusing) in range of their pl, 4-7 followed by their separation in second dimension based on molecular weight.

The protein spots which were exclusively expressed in the 4-NP induced proteome profile were excised from the gel, digested by trypsin and identified by mass spectrometry (of peptide fragments) following MASCOT search. One of the over expressed protein spot was identified as $\mathrm{ADH}$ with significant match score (Supplementary information spot 1) and few more protein spots, exclusively, expressed in 4-NP toxicoproteome were also identified but not with high values of confidence as per MASCOT database search. Among these, two proteins were identified as a cell division protein, electron transport flavoprotein and three hypothetical proteins all showing similarity with the respective representative proteins from Actinomycetales group of bacteria. The description and NCBI accession numbers of identified proteins with score and coverage information obtained

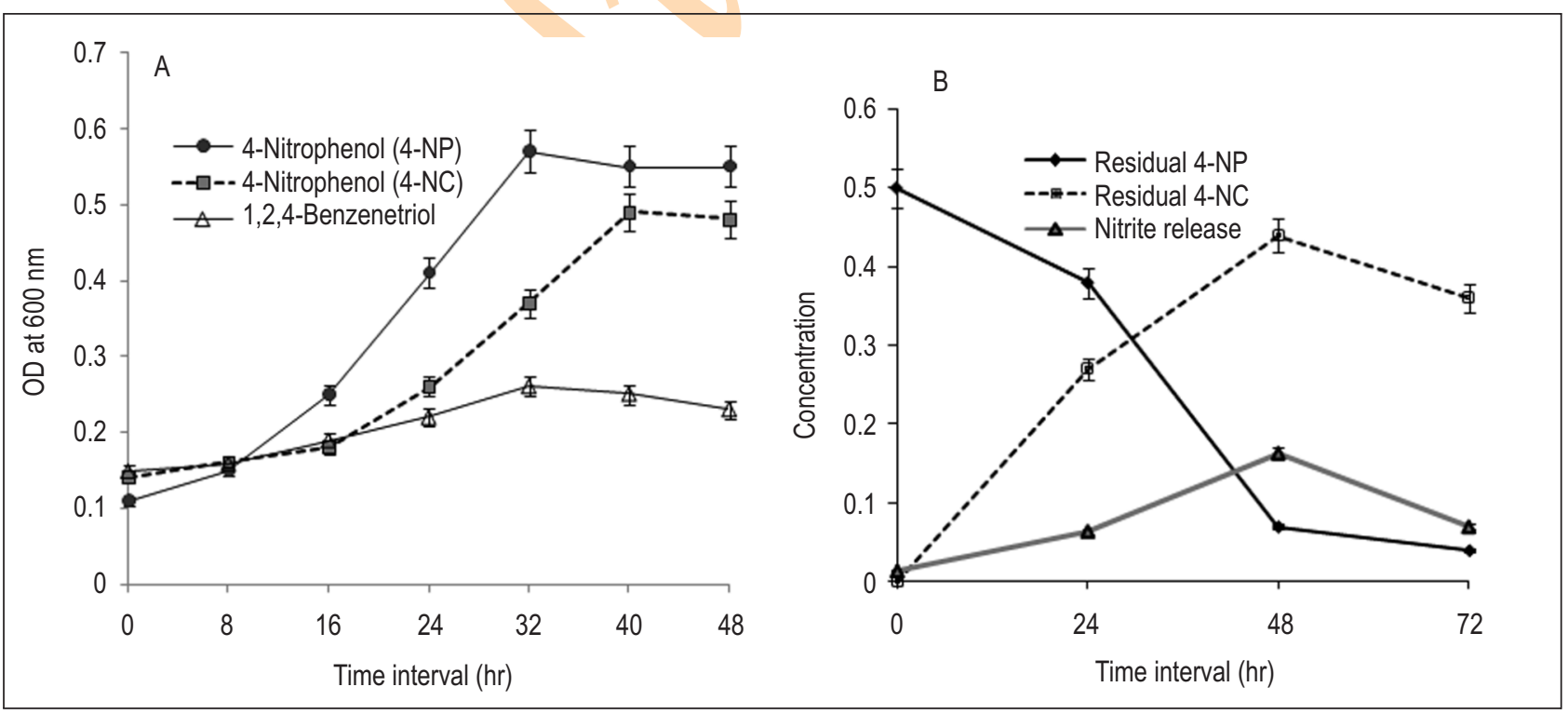

Fig.1: (A) Growth of the strain on various carbon source such as 4-NP, 4-NC and 1,2,4-Benzenetriol; (B) Detection of residuals of 4-NP, 4-NC and nitrite ions release during growth with time. 


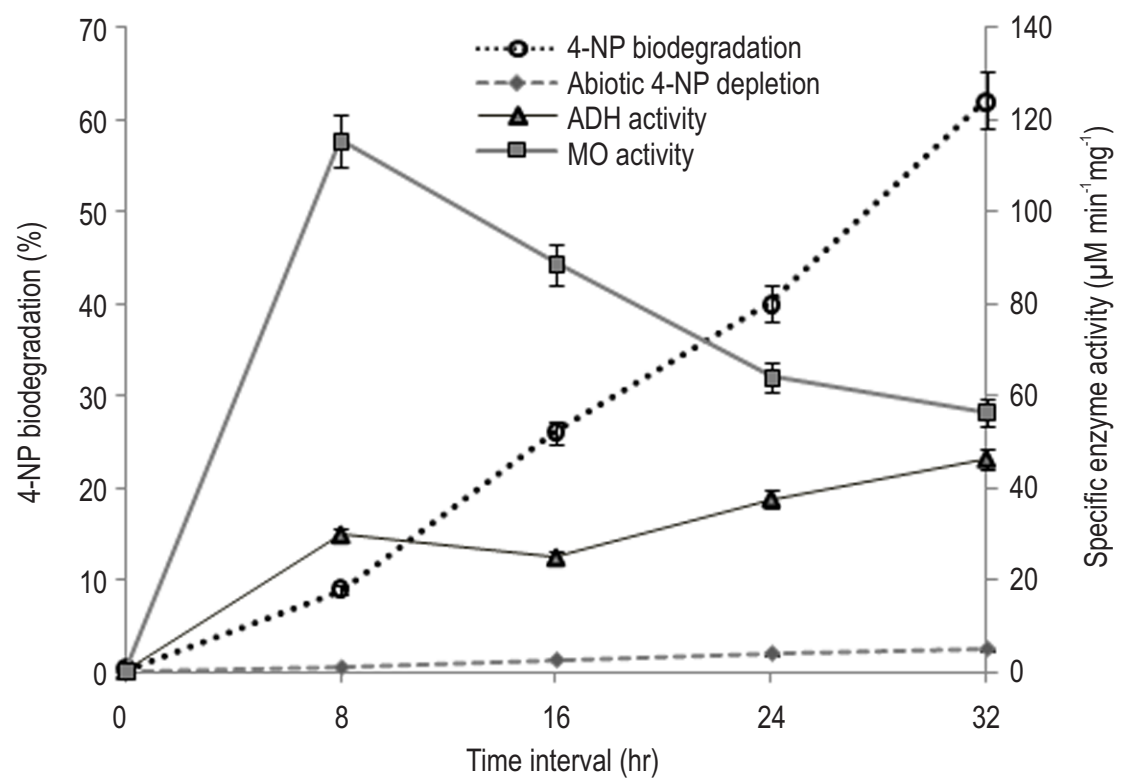

Fig.2 : Enzyme activity of alcohol dehydrogenase (ADH) and Monooxygenase (MO) during the 4-NP biodegradation.

from MASCOT search are documented in Table 1. A comparative proteome study revealed the role of proteins that are expressed by the strain in response to 4-NP. Upon exposure to the toxicant (4-NP), up-accumulation of several protein spots were observed, compared to glucose grown culture, which served as control. One spot among these was analyzed to contain protein that was identified as ADH through bioinformatics approach (MASCOT Search). However, till date, involvement of ADH protein in biodegradation of 4-NP has not been reported (Jörnvall et al., 2013). In this context, the involvement of ADH in 4-NP degradation is novel with respect to 4-NP degradation by bacteria. In order to strengthen the result of ADH over expression during 4-NP degradation, enzyme assay was carried out to determine activities of this enzyme in 4-NP treated and untreated culture at various growth time points of the strain. Specific enzyme activity of ADH was increased constantly during the late

Table 1: Summarized description of identified proteins spot expressed in the toxicoproteome of strain BUPNP1

\begin{tabular}{|c|c|c|c|c|c|c|}
\hline Spot No. & $\begin{array}{l}\text { Protein name } \\
\text { (source) }\end{array}$ & $\begin{array}{l}\mathrm{NCBI} \\
\text { accession no. }\end{array}$ & $\begin{array}{l}\mathrm{pl} \text { (theoretical } \\
\text { / practical) }\end{array}$ & $\begin{array}{l}\text { Scorel } \\
\text { coverage }(\%)^{(a)}\end{array}$ & $\begin{array}{l}\text { Matched } \\
\text { /searched }^{(b)}\end{array}$ & $\begin{array}{l}\text { Cellular localization } \\
\text { (score) }^{\circ}\end{array}$ \\
\hline 1. & $\begin{array}{l}\text { Alcohol dehydrogenase } \\
\text { (Rhodococcus sp.) }\end{array}$ & WP_016690905 & $5.45 / 5.8$ & $191 / 52$ & $22 / 87$ & $\begin{array}{l}\text { Cytoplasmic } \\
(9.97 / 4.36)\end{array}$ \\
\hline 2. & $\begin{array}{l}\text { Hypothetical protein MSMEG_ } \\
4961 \text { (Mycobacterium sp.) }\end{array}$ & YP_889212 & $9.99 / 5.5$ & $77 / 20$ & $10 / 59$ & $\begin{array}{l}\text { Extracellular } \\
(3.33 / 2.045)\end{array}$ \\
\hline 3. & $\begin{array}{l}\text { Cell division protein } \\
\text { (Corynebacterium sp.) }\end{array}$ & WP_014303624 & $4.98 / 6.7$ & $57 / 12$ & $5 / 9$ & $\begin{array}{l}\text { Cytoplasmic } \\
(7.5 / 4.537)\end{array}$ \\
\hline 4. & $\begin{array}{l}\text { MULTISPECIES: hypothetical } \\
\text { protein, (Streptomyces sp.) }\end{array}$ & WP_030180718 & $9.3 / 6.9$ & $62 / 35$ & $4 / 17$ & $\begin{array}{l}\text { Cytoplasmic } \\
(2.5 / 2.917)\end{array}$ \\
\hline 5. & $\begin{array}{l}\text { Hypothetical protein } \\
\text { (Streptomyces sp.) }\end{array}$ & WP_014674946 & $4.44 / 5.3$ & $76 / 70$ & $4 / 34$ & $\begin{array}{l}\text { Extracellular } \\
(2.5 / 1.957)\end{array}$ \\
\hline 6. & $\begin{array}{l}\text { Electron transfer flavoprotein } \\
\text { (Actinomyces sp.) }\end{array}$ & KGE99283 & $4.53 / 4.3$ & $63 / 25$ & $4 / 24$ & $\begin{array}{l}\text { Cytoplasmic } \\
(7.5 / 3.292)\end{array}$ \\
\hline
\end{tabular}

(a) MASCOT score and coverage (\%) of the total sequence of the corresponding protein by the matched peptides obtained during peptide mass fingerprinting; (b) Number of mass values matched out of total number of mass values searched; @ Cellular localization of the proteins predicted by the web-based software PSORTb, version 3.0.2 (http://www.psort.org/psortb/) and CELLO, version 2.5 (http://cello.life.nctu.edu.tw/). Probability scores (PSORTb/CELLO) are given in brackets 
exponential growth phase of the strain where major 4-NP degradation occurred which suggested that ADH expression was essential throughout the degradation process. The proteomics study also revealed that ADH expression is constitutive as it was also expressed in control set (glucose grown cells) and gets over expressed during major degradation of 4-NP. The 4-NP MO specific activity was observed higher during early exponential growth phase which involve initial steps of degradation involving nitro-aromatic ring cleavage (Vikram et al., 2013) where 4-NP depletion was just initiated with release of nitrite ions.

This result suggested that 4-NP MO is involved in initial breakdown of nitro-aromatic ring of 4-NP which also corroborate with earlier reports of 4-NP degradation (Ghosh et al., 2010; Chen et al., 2014). Existing literature also suggests that the primary enzyme involved in 4-NP degradation was membrane bound 4NP MO (Smith et al., 2011; Kumar et al., 2012). Activity of 4-NP MO were detected in crude cell extract of 4-NP treated cells but, unexpectedly, protein spots of this enzyme could not be recovered or identified during the toxicoproteome analysis. It could be due to the protocol adopted for total protein extraction was not good enough for isolation of membrane bound 4-NP MO. Bioinformatics approach was undertaken to illustrate probable function of all the proteins spot included hypothetical proteins in the toxicoproteome which is a well known approach to determine the protein functions (Bernhardt et al., 2013).

However, this type of bioinformatics analysis of hypothetical protein expressed in 4-NP treated cells is a completely a novel approach of identifying the proteins that are possibly involved in 4-NP degradation process. Reason for not having relevant match (Table 1) might be due to lack of similar studies. Proper understanding of these interrelated events, mediated by exclusively expressing proteins in presence of 4-NP, will have a successful impact towards designing better bioremediation strategies (Tyagi et al., 2011; Singh et al., 2015) not only for 4-NP contaminated sites but also for other toxic xenobiotic compounds.

The present toxicoproteomic analysis enlightens the idea of responsive proteins in the strain BUPNP1 that are expressed in response to 4-NP. Some hypothetical proteins expressed in 4-NP treated cells are completely novel proteins that are possibly involved in 4-NP degradation process.

\section{Acknowledgments}

We are grateful to SERB, New Delhi for financial support through project (SERB; SR/FT/LS-109/2010, New Delhi, India, completed in July, 2015). We are grateful to Dr. David E. Whitworth of Institute of Biological, Environmental and Rural Sciences, Aberystwyth University, UK, for his selfless, kindhearted-guidance, teachings, scientific discussion, help and encouragement. All his contribution towards our research understanding is thankfully acknowledged. We also thank Dr. Susan Girdwood of Aberystwyth University for help with HPLC.
Fund from Newton-Bhabha short term Ph. D. placement program (F.No. BT/IN/UK/DBT-BC/2015-16) is gratefully acknowledged. We thank Dr. Wriddhiman Ghosh of Bose Institute, Kolkata, India for providing laboratory facilities to carry out proteomic work. We are grateful to the Central Instrumental facility (CIF) of Bose Institute, Kolkata for help with isoelectric focusing and MALDI/MS analysis. KS was financially supported by DST-INSPIRE Fellowship (IF120104) while carrying out the experiments.

\section{References}

Alam, M. and W. Ghosh: Optimization of a phenol extraction-based protein preparation method amenable to downstream 2DE and MALDI-MS based analysis of bacterial proteomes. Proteomics, 14, 216-221 (2014).

Arora, P.K., A. Srivastava and V.P. Singh: Bacterial degradation of nitrophenols and their derivatives. J. Hazard. Mater., 266, 42-59 (2014).

Arora, P.K., C. Sasikala and C.V. Ramana: Degradation of chlorinated nitroaromatic compounds. Appl. Microbiol. Biotechnol., 93, 22652277 (2012)

Arora, P.K.: Metabolism of para-nitrophenol in Arthrobacter sp. J. Environ. Res. Manag., 3, 52-57 (2012).

Bernhardt, J., S. Michalik, B. Wollscheid, U. Völker and F. Schmidt: Proteomics approaches for the analysis of enriched microbial subpopulations and visualization of complex functional information. Curr. Opin. Biotechnol., 24, 112-119 (2013).

Chauhan, A., G. Pandey, N.K. Sharma, D. Paul, J. Pandey and R.K. Jain: p-Nitrophenol degradation via 4-Nitrocatechol in Burkholderia sp. SJ98 and cloning of some of the lower pathway genes. Environ. Sci. Technol., 44, 3435-3441 (2010).

Chen, Y.F., H. Chao and N.Y. Zhou: The catabolism of 2,4-xylenol and pcresol share the enzymes for the oxidation of para-methyl group in Pseudomonas putida NCIMB 9866. Appl. Microbiol. Biotechnol., 98, 1349-1356 (2014).

Chi, X.Q., J.J. Zhang, S. Zhao and N.Y. Zhou: Bioaugmentation with a consortium of bacterial nitrophenol-degraders for remediation of soil contaminated with three nitrophenol isomers. Environ. Pollut., 172, 33-41 (2013).

Ghosh, A., M. Khurana and A. Chauhan: Degradation of 4-Nitrophenol; 2-chloro-4-nitrophenol and 2,4-dinitrophenol by Rhodococcus imtechensis strain RKJ300. Environ. Sci. Technol., 44, 1069-1077 (2010).

Jörnvall, H., J. Hedlund, T. Bergman, Y. Kallberg, E. Cederlund and B. Persson: Origin and evolution of medium chain alcohol dehydrogenases. Chem. Biol. Interact., 202, 91-96 (2013).

Kalbende, P.P., M.V. Tarase and A.B. Zade: Preparation, characterization, and thermal degradation studies of $\mathrm{p}$ nitrophenol-based copolymer. J. Chem., 1, 9 (2013).

Karigar, C.H. and S.S. Rao: Role of microbial enzymes in the bioremediation of pollutants: A review. Enzyme Res., 2011, 11 (2011)

Karpievitch, Y.V., A.D. Polpitiya, G.A. Anderson, R.D. Smith and A.R. Dabney: Liquid chromatography mass spectrometry-based proteomics: Biological and technological aspects. Ann. Appl. Stat., 4, 1797-1823 (2010)

Kolvenbach, B.A., M. Lenz, D. Benndorf, E. Rapp, J. Fousek, C. Vlcek, A. Schäffer, F.L. Gabriel, H.P. Kohler and P.F. Corvini: Purification and characterization of hydroquinone dioxygenase from Sphingomonas sp. strain TTNP3. AMB Express, 1, 8 (2011).

Kooken, J., K. Fox, A. Fox, D. Altomare, K. Creek, D. Wunschel, S. 
Pajares-Merino, I. Martinez-Ballestros, J. Garaizar, O. Oyarzabal and M. Samadpour: Identification of staphylococcal species based on variations in protein sequences (mass spectrometry) and DNA sequence (sodA microarray). Mol. Cell. Probes, 28, 41-50 (2014)

Kou-San, J. and R. Parales: Nitroaromatic compounds from synthesis to biodegradation. Microbiol. Mol. Biol. Rev., 74, 250-272 (2010).

Kumar, S., S. Vikram and G.P. Raghava: Genome sequence of the nitroaromatic compound-degrading bacterium Burkholderia sp. strain SJ98. J. Bacteriol., 194, 3286 (2012).

Leilei, Z., H. Mingxin and Z. Suiyi: Biodegradation of p-nitrophenol by immobilized Rhodococcus sp. strain Y-1. Chem. Biochem. Eng. 26, 137-144 (2012)

Liu, P.P., J.J. Zhang and N.Y. Zhou: Characterization and mutagenesis of a two-component monooxygenase involved in para-nitrophenol degradation by an Arthrobacter strain. Int. Biodeterior. Biodegrad. 64,293-299 (2010)

Min, J., J.J. Zhang and N.Y. Zhou: A two-component para-nitropheno monooxygenase initiates a novel 2-chloro-4-nitrophenol catabolism pathway in Rhodococcus imtechensis RKJ300. Appl. Environ. Microbiol., 82, 714-723 (2016).

Pino, N.J., M.C. Dominguez and G.A. Penuela: Isolation of a selected microbial consortium capable of degrading methyl parathion and p-nitrophenol from a contaminated soil site. J. Environ. Sci. Hlth., 46, 173-180 (2011)

Pirie, P., F. Naeimpoor and P. Hejazi:A microcosm study on p-nitrophenol biodegradation in soil slurry by Alcaligenes faecalis: PlackettBurman Design. Iran. J. Chem. Eng., 8, 57-68 (2011).

Prakash, D., A. Chauhan and R. K. Jain: Plasmid-encoded degradation of p-nitrophenol by Pseudomonas putida: Biochem. Biophys. Res. Commun., 224, 375-381 (1996).

Rasheed, M.A., M. Lakshmi, P.L.S. Rao, M.S. Kalpana, D.J. Patil and A.M. Dayal: Carbon isotope fractionation studies of bacterial strain Rhodococcus rhodochrous MTCC 291. J. Environ. Biol., 34, 289$292(2013)$

Rubio, M.A., E. Lissi, N. Herrera, V. Perez and N. Fuentes: Phenol and nitrophenols in the air and dew waters of Santiago de Chile. Chemosphere, 86, 1035-1039 (2012).

Sengupta, K. and P. Saha: Identification of a newly isolated p-nitrophenol degrading strain characterized as Rhodococcus sp. BUPNP1. J. Environ. Res. Develop., 8, 431-436 (2014).

Sengupta, K., T.K. Maiti and P. Saha: Degradation of 4-nitrophenol in presence of heavy metals by a halotolerant Bacillus $\mathrm{sp}$. strain BUPNP2, having plant growth promoting traits. Symbiosis, 65 157-163 (2015)

Shen, W., W. Liu, J. Zhang, J. Tao, H. Deng, H. Cao and Z. Cui: Cloning and characterization of a gene cluster involved in the catabolism of p-nitrophenol from Pseudomonas putida DLL-E4. Bioresour. Technol., 101, 7516-7522 (2010).

Shevchenko, A., H. Tomas, J. Havlis and J.V. Olsen: In-gel digestion for mass spectrometric characterization of proteins and proteomes. Nat. Protoc., 1, 2856-2860 (2006).

Singh, A. and P. Malaviya: Optimization of culture parameters for tannery effluent bioremediation by Bacillus galactosidilyticus APBS5-3. J. Environ. Biol., 36, 1149-1152 (2015).

Smith, S.M., R. Balasubramanian and A.C. Rosenzweig: Metal reconstitution of particulate methane monooxygenase and heterologous expression of the pmoB subunit. Methods Enzymol., 495, 195-210 (2011).

Subhaschandrabose, S.R., K. Venkateshwarlu, K. Krishnan, R. Naidu, R. Lockington and M. Megharaj: Rhodococcus wratislaviensis strain 9: An efficient $p$-nitrophenol degrader with a great potential for bioremediation. J. Haz. Mat., 347, 176-183 (2018).

Tyagi, M., M.M. da Fonseca and C.C. de Carvalho: Bioaugmentation and bio-stimulation strategies to improve the effectiveness of bioremediation processes. Biodegradation, 22, 231-241 (2011).

Vikram, S., J. Pandey, F. Khan, G. Pandey and P.S. Raghava: Branching of PNP degradation pathway in Burkholderia sp strain SJ 98 evidences from genetic characterization of PNP cluster. AMP express, 2, 30 (2012a)

Vikram, S., J. Pandey, S. Kumar and G.P. Raghava: Genes involved in degradation of para-nitrophenol are differentially arranged in form of non-contiguous gene clusters in Burkholderia sp. strain SJ98. PLoS One, 8, e84766 (2013)

Vikram, S., S. Kumar, S. Subramanian and G.P.S. Raghava: Draft genome sequence of the Nitrophenol degrading Actinomycete Rhodococcus imtechensis RKJ300. J. Bacteriol., 194, 3543 (2012b).

Wei, M., J.J. Zhang, H. Liu and N.Y. Zhou: para-Nitrophenol 4monooxygenase and hydroxyquinol 1,2-dioxygenase catalyze sequential transformation of 4-nitrocatechol in Pseudomonas sp. strain WBC-3. Biodegradation, 21, 915-921 (2010).

Yamamoto, K., M. Nishimura, D. Kato, M. Takeo and S. Negoro: Identification and characterization of another 4-nitrophenol degradation gene cluster, nps, in Rhodococcus sp. strain PN1. J. Biosci. Bioeng., 111, 687-694 (2011).

Zhang, S., W. Sun, L. Xu, X. Zheng, X. Chu, J. Tian, N. Wu and Y. Fan: Identification of the para-nitrophenol catabolic pathway, and characterization of three enzymes involved in the hydroquinone pathway, in Pseudomonas sp. 1-7. BMC Microbiol., 12 (2012). doi: 10.1186/1471-2180-12-27

Zhang, W.M., J.J. Zhang, X. Jiang, H. Chao and N.Y. Zhou: Transcriptional activation of multiple operons involved in paranitrophenol degradation by Pseudomonas sp. strain WBC-3. Appl. Environ. Microbiol., 81, 220-230 (2015). 